\title{
The Present Situation of IT Outsourcing and Countermeasure
}

\author{
Xinyuan $\mathrm{Xi}^{1}$, Yingyu $\mathrm{Xu}^{2}$, Hiroyushi Todo ${ }^{3}$ \\ ${ }^{1}$ LeLe Mother’s Maternal Store Ltd., Shanghai, China; ${ }^{2}$ China Soft International Technology Service Ltd., Shanghai, China; ${ }^{3}$ Faculty \\ of Pharmaceutical Sciences, University of Toyama, Toyama, Japan. \\ Email: davidxxyspyshu@hotmail.com
}

Received June $16^{\text {th }}, 2013$; revised July $14^{\text {th }}, 2013$; accepted July $21^{\text {st }}, 2013$

Copyright (c) 2013 Xinyuan Xi et al. This is an open access article distributed under the Creative Commons Attribution License, which permits unrestricted use, distribution, and reproduction in any medium, provided the original work is properly cited.

\begin{abstract}
With the market competition intensifies, enterprises focusing on core business has become the most important rules of survival. Therefore, more and more enterprises adopt outsourcing as critical business initiatives due to its effectively reduce costs, enhancing the core competitiveness of enterprises and other characteristics. Duroc, a famous American management scholars had predicted: "In ten to fifteen years within any business background to support not only to do the work of creating turnover should be outsourced.” Do what you do best (your core competency) and outsource the rest. It has become an irreversible trend. In this paper, we will introduce the business value of IT outsourcing, discuss IT outsourcing industry's strengths and weaknesses, finally we will provide corresponding countermeasures based on the discussion.
\end{abstract}

Keywords: Outsourcing; IT Management; Countermeasure

\section{IT Outsourcing Introduction and Its Business Value}

In recent years, many IT Outsourcing studies have been conducted to address a variety of outsourcing research issues. They mainly focus on five major areas: organization, performance, decision, contract, and relationship [1]. Researches find that more and more organizations are looking to IT outsourcing through third party services providers. As the scope and complexity of IT expand, many organizations are less inclined to shoulder the burden of in-house development, since outsourcing allows them to better leverage their resources and focus on core applications to increase IT's value to corporate missions.

In this paper, we will introduce information technology outsourcing or ITO first, then we will discuss its disadvantages and corresponding action plans. First IT Outsourcing is a company's outsourcing of computer or Internet related work, such as programming, to other companies. It is used in reference to business process outsourcing or BPO, which is the outsourcing of the work that does not require much of technical skills.

Company's primary mission is creating profits and cost savings, but mature enterprise managers know that the best way to save costs is increasing the productivity of the unit employees. Modern enterprise internal structure is the combination of logistics, people, capital and information and they work closely with each other, in order to ensure effective operation of the enterprise. Enterprise internal IT system has been playing an increaseingly important role in the enterprise internal operation, there are many companies rely on IT system for business operation, any part of the IT system failure will be more or less affect the operation of enterprises, or even cause huge losses. How to ensure the normal operation of the organization? How to ensure that the business enterprise inside every employee productivity? This is the target enterprise IT system maintenance services. Some payment of maintenance fees, invite professional IT companies and professional IT system experts to achieve this goal is the most economic and the most rapid way though. Figure 1 below summarizes the benefits of IT outsourcing.

According to Corbett Group survey results about outsourcing market of more than 200 global large enterprise decision-making character, outsourcing has become an enterprise to enhance core competitiveness, reduce operational costs and strategic means to consolidate its market share. $97 \%$ of respondents say that the investment in outsourcing service increases greatly during the last 


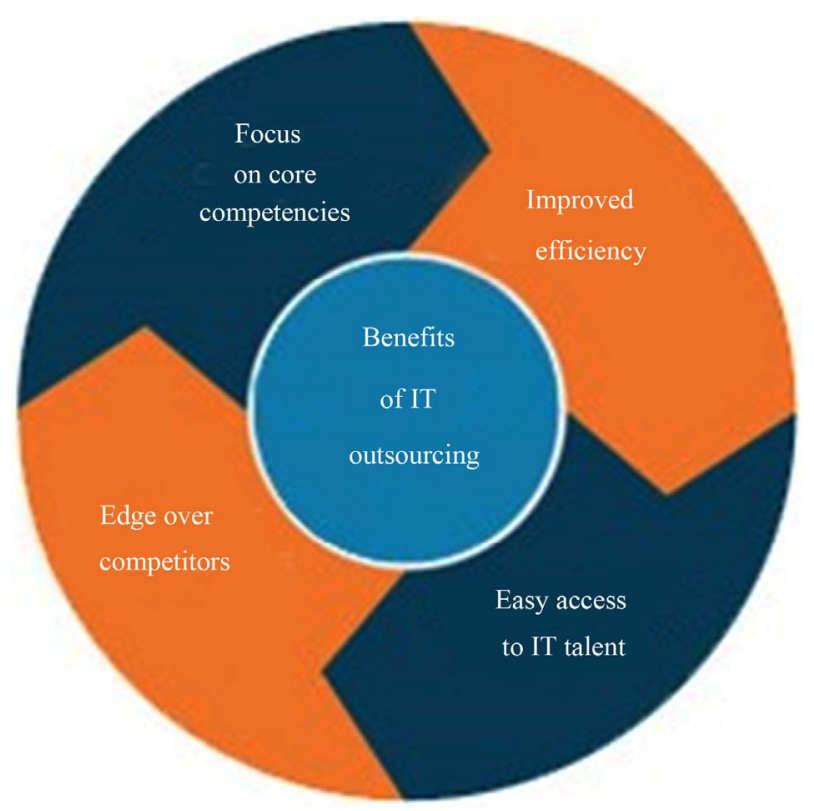

Figure 1. Benefits of IT outsourcing [2].

two years, and the momentum will continue to be maintained; $78 \%$ of respondents believe that outsourcing has become an important means of enterprise management, and $92 \%$ of respondents reflect that their corresponding business becomes outsourcing; $60 \%$ of the respondents are satisfied with the results implementing outsourcing, one of the most important aspect is the reduction in operating costs [3]. Also Corbett Group investigates the KPI Drivers of IT Outsourcing showed in Figure 2. Reducing operation cost is the first critical driver of IT Outsourcing.

IT outsourcing has long been the subject of debate, with questions centering on its ability to deliver projected benefits and business value. Still, few would argue its potential to impact the business in a positive way. Research has shown that companies engaged in IT outsourcing consistently outperform their peers, with better business performance and bottom-line results over the long term [4].

\section{IT Outsourcing's Current Status}

Most companies carry out projects using outsourcing, IT outsourcing risk awareness is strong, but there is no comparison to establish industry recognition for IT outsourcing management system best practices. Large companies are generally large-scale employees and rely on outsourcing vendors with a low level. The demand for IT outsourcing management urgency is little. Their own staffs in medium-sized and small companies are shortage and high dependence of outsourcing vendors, IT outsourcing management needs are more urgent.

From an international perspective, it is well known

\section{Key Drivers of IT Outsourcing}

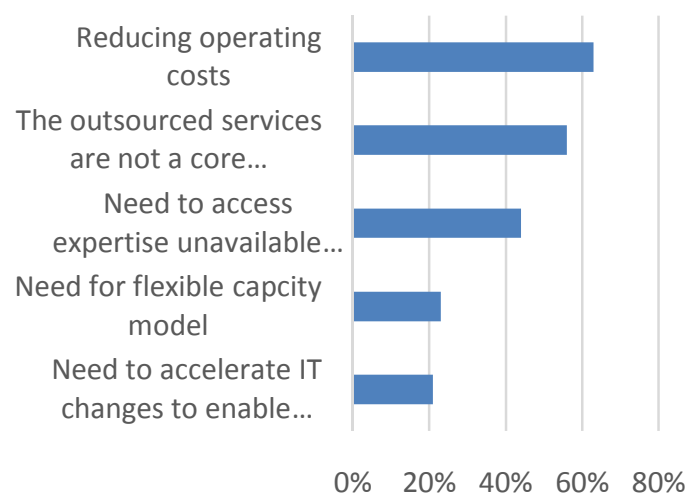

Figure 2. Key drivers of IT outsourcing.

that India has advantages in years of IT service experiences, optimized business process, first-class management, excellent English level, professional education system, plenty of excellent talents, a batch of competitive enterprises in large scale, strong support from the government and professional associations. All these advantages promote India's outsourcing industry to rank among the world's top. However, with some problems such as decreased talent supply and increased recruitment cost, cross-border corporations start to develop secondtier markets such as China, Indonesia and Philippines in order to diverse risks. China, together with India, is becoming one of the world's largest offshore markets with its abundant human resource, huge domestic demands, improved infrastructure of public transportation and communication, various market resources, strong attraction to foreigners, and strong support from central and local governments [5].

Based on research, future development of IT outsourcing business will be relatively stable and there will be no big ups and downs. With their own management level, medium-sized and small companies will adopt a more proactive strategy to carry out IT outsourcing activities. IT outsourcing development perspective will show the following trends [6]:

1) IT outsourcing market will become more professional, centralized and large-scale;

2) IT outsourcing models will continue to develop innovative, steady development of the overall size in the future;

3) Regulatory bodies for IT outsourcing risk management requirements will continue to increase.

It can be estimated that the global outsourcing industry will usher in the golden period of development such as specializing and integrating in the next 5 - 10 years. It's also a period of rapid development of domestic outsourcing industry through its service and technologies. 


\section{IT Outsourcing's Advantages and Disadvantages/Problems}

Outsourcing has become a strategic method to improve enterprises' core competitiveness, reduce operating costs and consolidate their market share. Outsourcing meets business objectives, encourages enterprises to focus on their core business and competencies, help enterprises in the evolving business and technology environment repositioning, which is the root cause of IT outsourcing. Additionally, it also has the following advantages:

1) Improve financial status: Some of the financial considerations can make use of outsourcing is especially attractive. For example, it may provide an opportunity for enterprises to liquidate its intangible IT assets to help tissue remodeling budget information systems by outsourcing, thereby improving corporate balance report and prevent enterprises from the uncertainty of future investment.

2) Cost savings and spending cuts: Compared with the internal IT department, outsourcing service companies can provide services at a lower cost; outsourcing of information services are provided by fixed costs into variable costs which can be avoided with the expansion of their business costs arising from the surge, enabling IT budgets remain linear growth and the cost is easier to predict and control, avoiding "IT black hole" phenomenon.

3) Gain information technologies and capabilities: IT Outsourcing is able to get the most advanced and cuttingedge technology and skills; Again, companies can take advantage of access to external equipment, services and other aspects of resources; they transfer ease outdated information technology and skills/risk to outsourcing companies; help enterprises and outsourcing companies sharing risks of new technologies.

4) Improve IT service levels: Outsourcing can improve the information service levels, improve service response speed and efficiency. Outsource companies in some areas than the internal information sector are always able to provide higher quality services, outsourcing routine operability and affordability of information services to enable enterprises to internal IT departments to focus on those who can really create value for the enterprise activities and applications, and enhance the efficiency of the internal IT department.

5) Promote organizational change: In the early days of a company, IT outsourcing can save a large amount of initial investment, effectively alleviate the tensions venture funding period; outsourcing helps mergering, acquisitions and restructuring activities.

6) Enhanced human resource allocation flexibility: By outsourcing, companies don't need to expand their hu- man scale due to the drop of personnel employed or the effort, cost pressures, and training expenses, increasing the flexibility of human resources.

7) Improve internal IT staff's ability to learn: outsourcing internal IT staff can reduce the pressure; outsourcing routine operation and maintenance work, the internal IT staff able to provide more learning new technologies, new solutions opportunities [7].

Meanwhile, in some cases, the company will be based on their own business development and IT building needs to develop a system on IT outsourcing management or process to standardize IT outsourcing management, so that the resulting level of outsourcing services can meet the desired objectives, however, as the company internal and external changes in the environment as well as the further outsourcing services in IT outsourcing management, there are still some of the more common questions:

1) IT outsourcing management system is weak and not under process, just based on previous experiences. Once the outsourcing has been initiated, managing IT Operation on the outside is still far from easy. The third party vendor may lack of process which can standardize the daily work and workflow. If there are changes in the vendor's personnel or organization, the company has to invest in building new partnerships and understanding how things are done in the new regime. They will need to put more efforts and cannot concentrate on their core business. Obviously, the management system is Inefficient.

2) Hidden Costs. When cost reduction is the objective of outsourcing, there is typically a promise of early cash flow benefits and long-term cost savings. Conversely, it may not know about future possible cost savings or foresee technological discontinuities. These issues are probably matters of judgment. Companies underestimate the setup costs, including redeployment costs, relocation costs, and longer-than-expected handoff or parallel running costs.

3) Employee relationships and Morale. Based on my experiences, Full-time employees may consider that they are supervisors of third party vendors' employees. Sometimes, they may not pay attention to the tone of voice, which can cause moral issues. Outsourcing engineers will not feel well and this will cause further attrition issue.

4) As a result of outsourcing, information security problems may occur. Security measures may need to be implemented to protect company data, employees, systems...everything can become a liability. You never know when data is accidentally going to walk off on an external hard-drive. All company or customer's data is sensitive and it is necessary to take security action for this point. 
5) Possible unstable technology skill level. We may face IT outsourcing engineers' attrition and moral issues, how can we assure that their technical skills will keep on a stable level? If the vendors' skill level does not keep unstable or advance, the cost-reduction potential is lessened, and unless further market testing is done, target setting is suboptimal [8,9].

\section{Main Issues and Solutions}

We may encounter several issues while applying IT Outsourcing. We conducted in-depth interviews with Industrial practitioners in two companies, one company is the PC vendor, and another is the IT world-class company and got the following results in Figure 3.

There are 2 main issues:

1) Lagged level of operational management:

Many companies copy the successful experience of the data, resulting in technical and management is not complete, meanwhile, it also lacks of technology and experience. Additionally due to lack of user surveys and analysis, application system maintainability and scalability is poor which will bring many unfavorable factors for the enterprise of the future development and practical application.

2) Staff high attrition rate and senior talent shortage:

Whether equipment providers, operator service providers or IT outsourcing companies, the staff attrition rate is relatively high. Some companies are even up to $60 \%$ staff turnover. Generally, IT outsourcing industry lacks of senior technical, marketing and operations management personnel. The main reason for this situation is that, practitioners are small and don't have practical experience. Although there are some successful experiences for reference, but after all, even with all aspects of national conditions to adapt, it is impossible to gain a large number of master advanced technology and operations management personnel groups in a short time. Finally it has not been established corresponding education and training system for IT outsourcing industry.

Regarding the solutions for the issues, enterprises should consider from IT outsourcing strategy formulation,

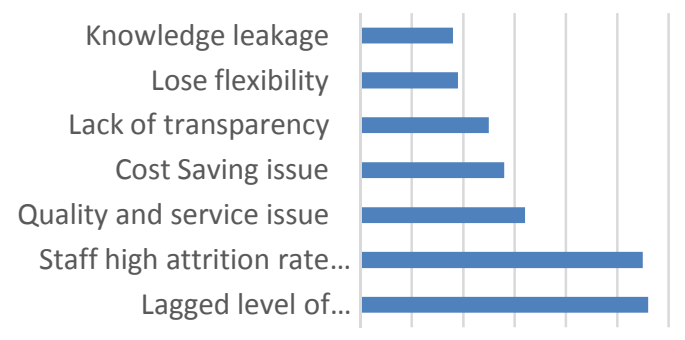

0\% 10\%20\%30\%40\%50\%60\%

Figure 3. IT outsourcing main issues. Source: Constructed by the author. implementation needs in the organization, processes and outsourcing key aspects of the life cycle. IT outsourcing strategy should meet the corporate business development strategy, IT strategic planning long-term objectives and regulatory requirements. Company's existing IT outsourcing management and IT management are important foundation to determine the maturity of IT outsourcing strategy is feasible, whether it can be implemented.

IT outsourcing risk management needs enterprises to develop practical risk assessment model, clear risk management process and good channels of communication. We should develop a risk assessment model for IT outsourcing various stages of considering the risks, including strategic risk, reputational risk, financial risk, compliance risk contracts, service delivery, risk, etc. Depending on the IT outsourcing risk, we can develop appropriate risk treatment measures (e.g. emergency plans, etc.). IT outsourcing risk treatment measures applied to various parts of outsourced activities, including supplier management, outsourcing personnel management, performance management, contract management. Outsourcing management should have a clear organizational structure and division of responsibilities clear boundaries processes and the system itself should be considered a comprehensive and thoughtful. It should be with the existing IT risk management, security management combined. Besides the implementation of processes systems, we also need operation from the perspective of staff awareness training and implementation. We believe that after taking the above actions, the IT sourcing can keep in a healthy status $[10,11]$.

We conducted another investigation with industrial practitioners in two typical IT outsourcing companies (Company A and B) which have taken the corresponding actions for covering above known issues. We can see Figure 4 clearly that the attrition rate is down and QoS (Quality of Service) is more stable.

\section{Conclusion}

Now that we have seen the advantages and disadvantages (main issues) associated with IT outsourcing, there are many things to consider about. Whether we use outsourcing or not, one thing is certain, we must know how to manage successful working relationships with the IT service providers. We should consider from IT outsourcing strategy formulation, implementation needs in the organization, processes and outsourcing key aspects of the life cycle. Also we need a rigorous and keep improving process or risk management to guide IT outsourcing management. It can make IT outsourcing projects institutionalization, standardization, and maintain in a stable level and keep improving. Thus our companies will pay attention on their core business and make more benefits, 


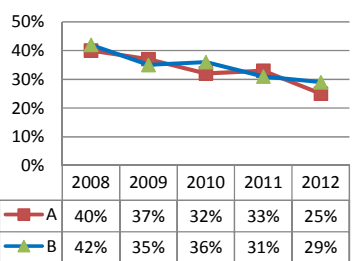

(a)

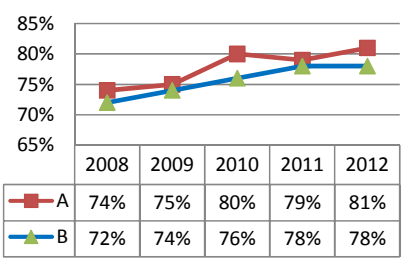

(b)
Figure 4. (a) Attration rate; (b) Customer satisfaction rate. Source: Constructed by the author.

not only by cutting down the costs.

\section{REFERENCES}

[1] J.-N. Lee, M. Q. Huynh, K. R. Chi-wai and S.-M. Pi, "The Evolution of Outsourcing Research: What is the Next Issue?" Proceedings of the 33rd Annual Hawaii International Conference on System Sciences, Maui, 4-7 January 2000, pp. 1-10.

[2] Sheetal, "How Does IT Outsourcing Enhance Your Business?”

http://www.virtualemployee.com/blogs/it-outsourcing-ca n-enhance-your-business

[3] Archstone Consulting, "The Business Value of IT Outsourcing Benchmark Report.”
[4] IBM Corporation, "Extend the Business Value of Outsourcing: Turning Provider Relationships into Innovation Partnerships.”

[5] B. Wang, "New Trends and Competition Status of International Outsourcing Industry." http://www.beyondsoft.com/insights/node/61

[6] G. Casey, “The Current State of Outsourcing and What It Means for the Business Analyst.”

[7] Corporate Computer Services, Inc., "IT Outsourcing: The Reasons, Risks and Rewards." http://www.corpcomputerservices.com/articles/outsourcin g-reasons

[8] M. J. Earl, "The Risks of Outsourcing IT." http://sloanreview.mit.edu/article/the-risks-of-outsourcing -it/

[9] J. Wallen, “10 Problems with Outsourcing IT,” 26 January 2012

http://www.techrepublic.com/blog/10things/10-problemswith-outsourcing-it/3016

[10] S. Rai, "Indians Fearing Repercussions of US Technology Outsourcing,” New York Times, 9 February 2004.

[11] The Current Global State of Outsourcing. http://seekingalpha.com/article/224884-the-current-global -state-of-outsourcing 